\title{
Association between parity and macrosomia in Shaanxi Province of Northwest China
}

\author{
Fangliang Lei ${ }^{1} \mathbb{D}$, Lili Zhang ${ }^{2 *}$, Yuan Shen ${ }^{1}$, Yaling Zhao ${ }^{1}$, Yijun Kang ${ }^{1}$, Pengfei $\mathrm{Qu}^{3}$, Baibing $\mathrm{Mi}^{1}$, \\ Shaonong Dang ${ }^{1}$ and Hong Yan ${ }^{4,5,6^{*}}$
}

\begin{abstract}
Objective: To explore the relationship between parity and macrosomia and provide the necessary reference for the maternal and children health service.

Method: A cross-sectional epidemiological survey with the purpose to assess the birth outcomes was conducted in Shaanxi province, China.

Results: The incidence of macrosomia in multiparas was higher than that in primiparas. Univariate analysis showed that maternal age $<25$ years, peasant/housework, living in rural areas and female infants were the protective factors of macrosomia. The possibility of having a macrosomic infant also increased with gestational age, maternal education level, household wealth index, living in Central Shaanxi and gestational diabetes. The generalized linear mixed models represented the association between parity and macrosomia. After adjusting for statistically significant factors in univariate analysis from model 1 to model 3, the risk of being born macrosomia was 1.26 times higher for a multipara compared to that for a primipara.

Conclusions: Present study indicated parity of two children was associated with increased risk for macrosomic births compared with parity of one child. Compared to primiparas, multiparas should far strengthen the prepregnancy education and the guidance during pregnancy to control pre-pregnancy body mass index and pregnancy weight, and keep the appropriate exercise and balanced diet.
\end{abstract}

Keywords: Parity, Macrosomia, Association, Primipara, Multipara

\section{Key-points}

- We found that parity was related to the occurrence of macrosomia. The incidence of macrosomia of multipara was higher than primipara, and the difference was statistically significant. Compared to primiparas, multiparas should far strengthen the pre-pregnancy education and the guidance during pregnancy to control pre-pregnancy body mass index and pregnancy weight, and keep the appropriate exercise and balanced diet.

\footnotetext{
* Correspondence: 782377048@qq.com; xjtu_yh.paper@aliyun.com 2Shaanxi Provincial People's Hospital, Xi'an 710068, Shaanxi, China ${ }^{4}$ Xi'an Jiaotong University, Health Science Center, Xi'an 710061, Shaanxi, China

Full list of author information is available at the end of the article
}

- After adjusting for statistically significant factors in univariate analysis, analysis based on generalized linear mixed models revealed that the risk of macrosomia was 1.26times higher for a secondborn child compared to a first born.

- The primary strength of the present analysis is the large sample size (27,351 single live births occurring from 2010 to 2013), which accounted for 9\% of neonates in Shaanxi Province. Therefore, our results can be generalized to the entire province as well as Northwest China.

\section{Introduction}

Birth weight (BW) is an important indication of mothers' and neonates' nutritional status, and may be the important determinant of infant's survival and future health, 
growth, and development [1]. Macrosomia is defined as birth weight greater than or equal to $4.0 \mathrm{~kg}$ [2-4]. Macrosomia prevalence in developed countries is between 5 and $20 \%$, although an increase of 15 to $25 \%$ has been reported in the past decades. With rapid economic growth in China in the past three decades, investments in education, healthcare and sanitation have increased accordingly. Chinese national health services survey showed that birth weight increased from $3186 \mathrm{~g}$ in 1993 to $3284 \mathrm{~g}$ in 1998 and to $3307 \mathrm{~g}$ in 2003 [5]. A rapid increase in rate of macrosomia has been reported in China. For example, one study about secular trends of macrosomia in southeast China reported an increase from $6.0 \%$ in 1994 to $7.8 \%$ in 2005 [2]. In Shanghai, the rates of macrosomia increased by 50\% between 1989 and 1999 .

Maternal complications of macrosomia include prolonged labor, labor augmentation with oxytocin, cesarean delivery, postpartum hemorrhage, infection, $3 \mathrm{rd}$ - and $4^{\text {rd }}$-degree perineal tears, thromboembolic events and anesthetic accidents [6, 7]. According the American College of Obstetricians and Gynecology (ACOG) practice bulletin macrosomic fetuses have a greater risk for perinatal asphyxia, meconium aspiration, clavicular fracture, brachial plexus injury, and shoulder dystocia [8]. Furthermore, macrosomic infants are at an increased risk of type 2 diabetes mellitus, hypertension, and obesity in adulthood [9-14].

Maternal parity is a well-recognized predictor of infant birthweight, with the lowest birthweights observed among infants born to nulliparous women [15-20]. Birthweight differences across parity have also been shown in prior sibling analyses [15-20]. One prior study reported a birthweight difference of $118 \mathrm{~g}$ between first and second born infants; however, when limited only to sibling pairs the difference was even greater at $138 \mathrm{~g}$ [21]. Most prior studies focused on the association between parity and birthweight $[21,22]$. In addition, several studies have reported that the multiparity is one of the risk factors for macrosomia, or explained the association between parity and macrosomia [23-25]. However, few studies from China were performed for the association between parity and macrosomia. A large population-based sampling survey which was conducted in Shaanxi province of Northwest China to assess birth outcomes allowed us to study the relationship parity and macrosomia.

\section{Materials and methods}

\section{Study design and participants}

The cross-sectional study was executed in Shaanxi province of Northwest China from August to November 2013. The infants born during 2010-2013 and their mothers were the objects of the research. Because of the different population density and fertility rates between rural and urban areas in the whole province, a hierarchical, polystage, probability-proportional-to-size sampling method was used in the present research. In China, administrative organization was divided into 3-hierarchy frames. Counties, townships and villages constitute the rural areas. Independent of rural areas, districts, streets and communities constitute the urban areas. In the first place, 20 counties and 10 districts were randomly selected from the whole province. Then, six townships and three streets were randomly sampled in the chosen counties and districts. Afterwards we selected six villages from per chosen township and six communities from per chosen street randomly. A random sampling method was used to select 30 babies born during 2010-2013 and their mothers in every chosen village, and, 60 in every sampled community. Expected sample size of our study was approximately 32,400 infants and their mothers. But 2373 subjects were unwilling to join in the study (response rate: $92.68 \%$ ). Therefore 28,644 single live infants were chosen for this project. And 481 objects were removed for unknown birth weight and childbearing history. Moreover, 812 subjects were removed who had more than 3 children. In the end, a total of 27,351 singleton live infants were selected.

\section{Data collection}

All data was stated by the mothers of the chosen children, including socio-demographical information and information on maternal lifestyles during pregnancy. Xi'an Jiaotong University Health Science Center devised all questionnaires. Ten field teams that every team comprised 10-12 members were formed for these counties or districts. As soon as completing every questionnaire, the supervisors were responsible for detecting any errors and/or imperfect information. All data collection was completed in the local village clinics and community health service centers. Our study was sustained by the local hospitals and health administrative departments as well as the Shaanxi province Ministry of Health.

\section{Study variables}

Controlling for potential confounding factors was necessary when determining the relationship parity and macrosomia. Based on the currently available body of knowledge and the nature of our data, we selected potential confounding factors from three groups of variables: children, family and mothers. The factors included within the children group were the child's sex and gestational age. The factors included within the family group were economic conditions, region and residence. The factors included within the mother group were maternal education level, age at the child's birth, occupation and gestational diabetes.

Primipara: A woman who has borne only one living child.

Multipara: A woman who has given birth to 2 living children. 


\section{Statistical analysis}

A database was designed by EpiData version 3.02, and data entry was duplicated. Firstly, the characteristics of participants were summarized using means \pm SDs for normally distributed continuous variable. The categorical variables were described using count and proportions. The $\chi^{2}$ test was used to prove differences in proportions between groups. On account of the multilevel hierarchical structure of the data, the generalized linear mixed model approach was used, which is a good method for analyzing data with a hierarchical structure and can be applied in sampling investigations. Ultimately, a 2-level analysis was performed to adjust for the effect of randomization by counties/districts and to analyze the associations between parity and macrosomia with county/districts to level 2 and individual to level 1 by nine potential confounding factors. Model 1 adjusted for gestational age and sex of infants. Model 2 adjusted for the variables in model 1 plus the relevant maternal characteristics, including maternal education level, age at the child's birth, occupation and gestational diabetes. Model 3 adjusted for the variables in model 2 and the status of family characteristics (including economic conditions, region and residence). All statistical analyses were performed using SAS 9.3 (SAS Institute Inc., Cary, NC). Two-tailed $P<0.05$ was considered statistically significant.

\section{Result}

\section{Baseline characteristics of the participants}

Of the infants, boys accounted for $53.92 \%$ of total infants. Amongst the region of the infants, infants in Central Shaanxi, Northern Shaanxi and Southern Shaanxi accounted for $54.41,25.06$ and $20.53 \%$ respectively. The childbearing age of mothers was $26.92 \pm 4.65$ years and approximately $39.45 \%$ of them were educated beyond senior high school. The other details of the sample and distribution of the major demographic variables are shown in Table 1.

\section{Status of neonatal birth weight}

The average birth weight of 27,351 newborns was $3267.21 \pm 455.90 \mathrm{~g}$. The neonatal average birth weight of the primipara was $3262.18 \pm 452.36 \mathrm{~g}$, and that of the multipara was $3275.07 \pm 461.29 \mathrm{~g}$. Neonatal birth weight of the multipara was higher than that of the primipara, and the difference was statistically significant. The incidence of low birth weight infants was $3.38 \%$, and the incidence rate of macrosomia was $6.79 \%$. Among the 27 , 351 women of childbearing age surveyed, 16,677(60.97\%) women were primiparas, and 10,675(39.03\%) were multiparas. The birth weight status of the children for primiparas and multiparas were shown in Table 2. The incidence of macrosomia in multiparas was higher than
Table 1 Characteristics of the study population

\begin{tabular}{|c|c|c|c|}
\hline Baseline characteristics & Primipara & Multipara & $P$ \\
\hline Maternal age, year ${ }^{a}$ & $25.19(3.69)$ & $29.60(4.71)$ & $<0.001$ \\
\hline Gestational age, week $^{a}$ & $39.65(1.29)$ & $39.64(1.24)$ & 0.549 \\
\hline \multicolumn{4}{|l|}{ Sex of infants, $n(\%)$} \\
\hline Boy & $8789(52.70)$ & $5959(55.82)$ & \multirow[t]{2}{*}{$<0.001$} \\
\hline Girl & $7887(47.30)$ & $4716(44.18)$ & \\
\hline \multicolumn{4}{|l|}{ Season of birth, n (\%) } \\
\hline Spring & $4237(25.41)$ & $2803(26.26)$ & \multirow[t]{4}{*}{$<0.001$} \\
\hline Summer & $3878(23.25)$ & $2669(25.00)$ & \\
\hline Fall & $4166(24.98)$ & $2595(24.31)$ & \\
\hline Winter & $4395(26.36)$ & $2608(24.43)$ & \\
\hline \multicolumn{4}{|l|}{ Region, n (\%) } \\
\hline Central Shaanxi & $9513(57.05)$ & $5367(50.28)$ & \multirow[t]{3}{*}{$<0.001$} \\
\hline Northern Shaanxi & $3750(22.49)$ & $3105(29.09)$ & \\
\hline Southern Shaanxi & $3413(20.46)$ & $2203(20.63)$ & \\
\hline \multicolumn{4}{|l|}{ Mother's education, n (\%) } \\
\hline Primary school or less & $917(5.51)$ & $2095(19.67)$ & \multirow[t]{4}{*}{$<0.001$} \\
\hline Junior high school & $6992(42.03)$ & $6524(61.25)$ & \\
\hline Senior high school & $4044(24.31)$ & $1559(14.64)$ & \\
\hline College and above & $4683(28.15)$ & $473(4.44)$ & \\
\hline \multicolumn{4}{|l|}{ Residence, n (\%) } \\
\hline Urban area & $4643(27.95)$ & $1135(10.68)$ & \multirow[t]{2}{*}{$<0.001$} \\
\hline Rural area & $11,968(72.05)$ & $9492(89.32)$ & \\
\hline \multicolumn{4}{|l|}{ Mother's occupation, n (\%) } \\
\hline Peasant/Housework & $8932(53.56)$ & $8275(77.52)$ & \multirow[t]{2}{*}{$<0.001$} \\
\hline Other & $7744(46.44)$ & $2400(22.48)$ & \\
\hline \multicolumn{4}{|c|}{ Household Wealth Index, n (\%) } \\
\hline Poorest & $3302(22.10)$ & $2903(29.13)$ & \multirow[t]{3}{*}{$<0.001$} \\
\hline Middle & $7765(51.96)$ & $5605(56.25)$ & \\
\hline Richest & $3876(25.94)$ & $1456(14.62)$ & \\
\hline
\end{tabular}

${ }^{\mathrm{a}}$ Reported as mean and SD (standard deviation)

that in primiparas, and the difference was statistically significant $(P<0.001)$.

\section{Univariate analysis of possible influencing factors of macrosomia}

Univariate analysis results showed that maternal age $<$ 25 years, peasant/housework, living in rural areas and female infants were the protective factors of macrosomia. And the possibility of having a macrosomic infant also increased with gestational age, maternal education level, household wealth index, living in Central Shaanxi and gestational diabetes. Compared with primipara, multipara was also associated with an increased risk of delivering a macrosomic infant (Table 3). 
Table 2 Neonatal birth weight of the primiparas and multiparas

\begin{tabular}{llrll}
\hline $\begin{array}{l}\text { Pregnant } \\
\text { women }\end{array}$ & $N$ & Normal & $\begin{array}{l}\text { Low birth } \\
\text { weight }\end{array}$ & Macrosomia \\
\hline Primipara & 16,676 & $15,055(90.28)$ & $560(3.36)$ & $1061(6.36)$ \\
Multipara & 10,675 & $9515(89.13)$ & $364(3.41)$ & $796(7.46)$ \\
Total & 27,351 & $24,570(89.83)$ & $924(3.38)$ & $1857(6.79)$ \\
$X^{2}$ & & & 0.05 & 12.31 \\
$P$ & & & 0.817 & $<0.001$ \\
\hline
\end{tabular}

\section{Analysis of the relationship parity and macrosomia}

In Fig. 1, the GLMM results obtained for macrosomia as an outcome variable represent the association between parity and macrosomia. After adjusting for statistically significant factors in univariate analysis from model 1 to model 3, the odds ratio (OR) showed that the risk of macrosomia in multipara is higher than in primipara. Furthermore, the 3 odds ratios were similar, which indicated that the models were stable. Specifically, a statistically significant association between parity and

Table 3 Univariate analysis of possible influencing factors of macrosomia

\begin{tabular}{|c|c|c|c|c|c|}
\hline Variables & $\beta$ & Standard Error & Wald $x^{2}$ & $P$ & $O R(95 \% C l)$ \\
\hline \multicolumn{6}{|l|}{ Maternal age } \\
\hline$Y<25$ & -0.422 & 0.057 & 54.138 & $<0.001$ & $0.656(0.586,0.734)$ \\
\hline $25 \leq Y<30$ & Ref & & & & \\
\hline$Y \geq 30$ & 0.047 & 0.060 & 0.615 & 0.433 & $1.048(0.932,1.180)$ \\
\hline \multicolumn{6}{|l|}{ Gestational age } \\
\hline$W<37$ & -0.983 & 0.228 & 18.584 & $<0.001$ & $0.374(0.239,0.585)$ \\
\hline $37 \leq W<42$ & Ref & & & & \\
\hline$W \geq 42$ & 0.414 & 0.129 & 10.272 & 0.001 & $1.513(1.175,1.950)$ \\
\hline \multicolumn{6}{|l|}{ Region } \\
\hline Southern Shaanxi & Ref & & & & \\
\hline Central Shaanxi & 0.155 & 0.064 & 5.799 & 0.016 & $1.167(1.029,1.324)$ \\
\hline Northern Shaanxi & 0.097 & 0.074 & 1.751 & 0.186 & $1.102(0.954,1.274)$ \\
\hline \multicolumn{6}{|l|}{ Mother's education } \\
\hline Junior high school and below & Ref & & & & \\
\hline Senior high school & 0.138 & 0.062 & 4.992 & 0.025 & $1.148(1.017,1.297)$ \\
\hline College and above & 0.428 & 0.059 & 53.505 & $<0.001$ & $1.534(1.368,1.721)$ \\
\hline \multicolumn{6}{|l|}{ Household Wealth Index } \\
\hline Poorest & Ref & & & & \\
\hline Middle & 0.180 & 0.065 & 7.597 & 0.006 & $1.197(1.053,1.361)$ \\
\hline Richest & 0.423 & 0.074 & 32.368 & $<0.001$ & $1.527(1.320,1.766)$ \\
\hline \multicolumn{6}{|l|}{ Residence } \\
\hline Urban area & Ref & & & & \\
\hline Rural area & -0.435 & 0.054 & 65.737 & $<0.001$ & $0.647(0.582,0.719)$ \\
\hline \multicolumn{6}{|l|}{ Mother's occupation } \\
\hline Peasant/Housework & -0.238 & 0.049 & 23.820 & $<0.001$ & $0.788(0.717,0.867)$ \\
\hline Other & Ref & & & & \\
\hline \multicolumn{6}{|l|}{ Parity } \\
\hline Primipara & Ref & & & & \\
\hline Multipara & 0.170 & 0.049 & 12.290 & $<0.001$ & $1.186(1.078,1.304)$ \\
\hline \multicolumn{6}{|l|}{ Gestational diabetes } \\
\hline No & Ref & & & & \\
\hline Yes & 1.139 & 0.321 & 12.619 & $<0.001$ & $3.123(1.666,5.855)$ \\
\hline \multicolumn{6}{|l|}{ Sex } \\
\hline Boy & Ref & & & & \\
\hline Girl & -0.602 & 0.051 & 139.141 & $<0.001$ & $0.548(0.496,0.605)$ \\
\hline
\end{tabular}




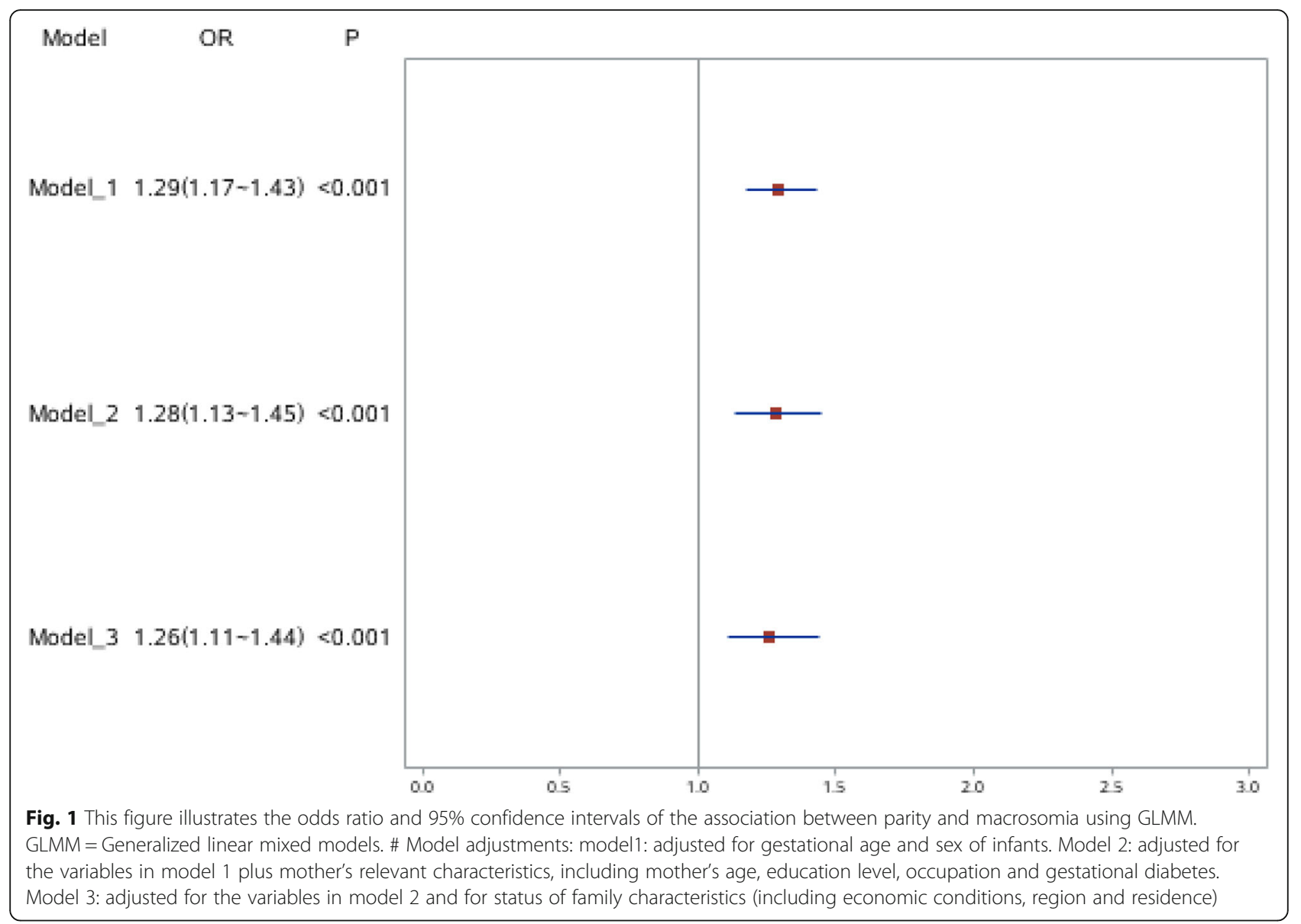

macrosomia was found. The risk of being born macrosomia was 1.26 times higher for a multipara compared to that for a primipara.

\section{Discussion}

\section{Main findings}

We found that parity was related to the occurrence of macrosomia. The incidence of macrosomia of multipara was higher than primipara, and the difference was statistically significant. After adjusting for statistically significant factors in univariate analysis, analysis based on generalized linear mixed models revealed that the risk of macrosomia was 1.26 times higher for a secondborn child compared to a first born.

\section{Data interpretation and comparisons with previous studies}

The association between parity and macrosomia has been previously investigated in a few studies conducted elsewhere, and increased parity is associated with higher risk of fetal macrosomia [23, 24]. Multiparity is one of the most important risk factors for macrosomia, according to the American College of Obstetricians and Gynecologists' Committee on Practice Bulletins-Obstetrics
[26]. The rate of fetal macrosomia in multiparous women has been shown to be $2-3$ times higher than that in control group in the majority of studies [27]. Faith Agbozo. etal noted that the parity of two to three children was related to raised risk for macrosomia [28]. The aforementioned studies illuminated the relationship between parity and macrosomia and provided some references and evidences for our research.

The present cross-sectional study indicated parity of two children was associated with increased risk for fetal macrosomia. Compared to primiparas, multiparas should far strengthen the pre-pregnancy education and the guidance during pregnancy to control pre-pregnancy body mass index and pregnancy weight, and keep the appropriate exercise and balanced diet in order to reduce the incidence of macrosomia.

\section{Strengths and limitations}

The primary strength of the present analysis is the large sample size (27,351 single live births occurring from 2010 to 2013), which accounted for $\sim 9 \%$ of neonates in Shaanxi Province [29]. Therefore, our results can be generalized to the entire province as well as Northwest China. Another strength of this study is that the birth 
weight data collected from birth certificates was accurate to the nearest $10 \mathrm{~g}$. Moreover, the generalized linear mixed models adjusted for relevant covariates were generated to further elucidate the association between parity and macrosomia. Limitations of our data should also be noted. Some major confounders, including pre-pregnancy BMI, diet, weight gain during pregnancy and so on, were not adjusted for because we lacked these data [30, 31]. Nevertheless, the current study is the first and largest survey that has presently been conducted in Northwest China, and provides the best information on the relationship between parity and macrosomia in this geographical region.

\section{Conclusions}

The present cross-sectional study indicated parity of two children was associated with increased risk for macrosomic births compared with parity of one child. Compared to primiparas, multiparas should far strengthen the prepregnancy education and the guidance during pregnancy to control pre-pregnancy body mass index and pregnancy weight, and keep the appropriate exercise and balanced diet in order to reduce the incidence of macrosomia.

\section{Acknowledgments}

The all authors would like to thank the sponsors and all participants in this study, all staff who coordinated field work and all investigators who contributed to data collection.

\section{Financial support}

The study was sponsored National Natural Science Foundation of China (grant number 81230016), Shaanxi Health and Family Planning Commission (grant number Sxwsjswzfcght2016-013), National Key R\&D Program of China (grant Number 2017YFC0907200, 2017YFC0907201), Chinese National Natural Science Foundation for Young Scientists (grant number 81703245) and Shaanxi natural science basic research (grant number 2014JM2-8153). These sponsors had no role in the design, analysis, interpretation of data, or composition of this article or the decision to submit the paper for publication.

\section{Authors' contribution}

FL designed the study, collected the data, conducted the data analysis and prepared the manuscript. FL had full access to all data in the study and assumed responsibility for the integrity of the data and the accuracy of the data analysis. LZ and YS designed the study and the analysis and prepared the manuscript. $Y Z$ and $Y K$ assisted with the data analysis and reviewed the manuscript. PQ and BM participated in the design of the study and performed the statistical analysis. SD and HY conceived of the study, and participated in its design and coordination and helped to draft the manuscript. All authors read and approved the final manuscript.

\section{Funding}

The study was sponsored National Natural Science Foundation of China (grant number 81230016), Shaanxi Health and Family Planning Commission (grant number Sxwsjswzfcght2016-013), National Key R\&D Program of China (grant Number 2017YFC0907200, 2017YFC0907201), Chinese National Natural Science Foundation for Young Scientists (grant number 81703245) and Shaanxi natural science basic research (grant number 2014JM2-8153).

\section{Availability of data and materials}

The datasets generated and/or analysed during the current study are not publicly available. Because the data collection has been completed together by the research team, and the team has contributed a lot of effort for it. And it is available from the corresponding author on reasonable request.

\section{Ethics approval and consent to participate}

This study was approved by the Human Research Ethics Committee of the Xi'an JiaoTong University Health Science Center (No 2012008), China. Written informed consent was obtained from all study participants after a detailed briefing on the purpose, process and confidentiality of the research.

\section{Consent for publication}

Not applicable.

\section{Competing interests}

The authors declare that they have no competing interests.

\section{Author details}

'Department of Epidemiology and Health Statistics, School of Public Health, Xi'an Jiaotong University Health Science Center, Xi'an 710061, Shaanxi, China. ${ }^{2}$ Shaanxi Provincial People's Hospital, Xi'an 710068, Shaanxi, China. ${ }^{3}$ Assisted Reproduction Center, Northwest women and children's Hospital, Xi'an 710003, Shaanxi, China. ${ }^{4}$ Xi'an Jiaotong University, Health Science Center, Xi'an 710061, Shaanxi, China. ${ }^{5}$ Nutrition and Food Safety Engineering Research Center of Shaanxi Province, Xi'an 710061, Shaanxi, China. ${ }^{6}$ Key Laboratory of Environment and Genes Related to Diseases (Xi'an Jiaotong University), Ministry of Education, Xi'an 710061, Shaanxi, China.

Received: 26 September 2019 Accepted: 29 January 2020

Published online: 18 February 2020

\section{References}

1. Gage TB, Fang F, O'Neill E, Dirienzo G. Maternal education, birth weight, and infant mortality in the United States. Demography. 2013;50(2):615-35.

2. Lu Y, Zhang J, Lu X, Xi W, Li Z. Secular trends of macrosomia in Southeast China, 1994-2005. BMC Public Health. 2011;11:818.

3. Koyanagi A, Zhang J, Dagvadorj A, Hirayama F, Shibuya K, Souza JP, et al. Macrosomia in 23 developing countries: an analysis of a multicountry, facility-based, cross-sectional survey. Lancet. 2013;381(9865):476-83.

4. Ye J, Torloni MR, Ota E, Jayaratne K, Pileggi-Castro C, Ortiz-Panozo E, et al. Searching for the definition of macrosomia through an outcome-based approach in low- and middle-income countries: a secondary analysis of the WHO global survey in Africa, Asia and Latin America. BMC Pregnancy Childbirth. 2015;15:324.

5. Center for Health Statistics and Information, MOH, China (2004) An analysis report of National Health Services Survey in China, 2003 (in Chinese). Centre for Health Statistics and Information of Ministry of Health of People's Republic of China, Beijing, China.

6. Asplund CA, Seehusen DA, Callahan TL, Olsen C. Percentage change in antenatal body mass index as a predictor of neonatal macrosomia. Ann Fam Med. 2008;6(6):550-4.

7. Boulet SL, Alexander GR, Salihu HM, Pass M. Macrosomic births in the United States: determinants, outcomes, and proposed grades of risk. Am J Obstet Gynecol. 2003;188(5):1372-8.

8. Chatfield J. ACOG issues guidelines on fetal macrosomia. American College of Obstetricians and Gynecologists. Am Fam Physician. 2001;64(1):169-70.

9. Hermann GM, Dallas LM, Haskell SE, Roghair RD. Neonatal macrosomia is an independent risk factor for adult metabolic syndrome. Neonatology. 2010; 98(3):238-44.

10. Boney CM, Verma A, Tucker R, Vohr BR. Metabolic syndrome in childhood: association with birth weight, maternal obesity, and gestational diabetes mellitus. Pediatrics. 2005;115(3):e290-6.

11. Oken E, Gillman MW. Fetal origins of obesity. Obes Res. 2003;11(4):496-506.

12. Lawn JE, Mwansa-Kambafwile J, Horta BL, Barros FC, Cousens S. 'Kangaroo mother care' to prevent neonatal deaths due to preterm birth complications. Int J Epidemiol. 2010;39(Suppl 1):i144-54.

13. Halileh S, Abu-Rmeileh N, Watt G, Spencer N, Gordon N. Determinants of birthweight: gender based analysis. Matern Child Health J. 2008;12(5): $606-12$.

14. Mohammad K, Kassab M, Gamble J, Creedy DK, Foster J. Factors associated with birth weight inequalities in Jordan. Int Nurs Rev. 2014;61(3):435-40.

15. Shah PS. Parity and low birth weight and preterm birth: a systematic review and meta-analyses. Acta Obstet Gynecol Scand. 2010;89(7):862-75.

16. Beaty TH, Skjaerven R, Breazeale DR, Liang KY. Analyzing sibship correlations in birth weight using large sibships from Norway. Genet Epidemiol. 1997: 14(4):423-33. 
17. Melve KK, Skjaerven R, Oyen N. Families with a perinatal death: is there an association between the loss and the birthweight of surviving siblings? Paediatr Perinat Epidemiol. 2002;16(1):23-32.

18. Oyen N, Haglund B, Skjaerven R, Irgens LM. Maternal smoking, birthweight and gestational age in sudden infant death syndrome (SIDS) babies and their surviving siblings. Paediatr Perinat Epidemiol. 1997;11(Suppl 1):84-95.

19. Skjaerven R, Gjessing HK, Bakketeig LS. New standards for birth weight by gestational age using family data. Am J Obstet Gynecol. 2000;183(3):689-96.

20. Pedersen CB, Sun Y, Vestergaard M, Olsen J, Basso O. Assessing fetal growth impairments based on family data as a tool for identifying high-risk babies. An example with neonatal mortality. BMC Pregnancy Childbirth. 2007;7:28.

21. Wilcox MA, Chang AM, Johnson IR. The effects of parity on birthweight using successive pregnancies. Acta Obstet Gynecol Scand. 1996;75(5):459-3.

22. Hinkle SN, Albert PS, Mendola P, Sjaarda LA, Yeung E, Boghossian NS, et al. The association between parity and birthweight in a longitudinal consecutive pregnancy cohort. Paediatr Perinat Epidemiol. 2014;28(2):106-15.

23. Dor N, Mosberg H, Stern W, Jagani N, Schulman H. Complications in fetal macrosomia. N Y State J Med. 1984;84(6):302-5.

24. Sack RA. The large infant. A study of maternal, obstetric, fetal, and newborn characteristics; including a long-term pediatric follow-up. Am J Obstet Gynecol. 1969;104(2):195-204.

25. Okun N, Verma A, Mitchell BF, Flowerdew G. Relative importance of maternal constitutional factors and glucose intolerance of pregnancy in the development of newborn macrosomia. J Matern Fetal Med. 1997:6(5):285-90.

26. American College of Obstetricians and Gynecologists. Practice Bulletin No. 173: Fetal Macrosomia. Obstet Gynecol. 2016;128(5):e195-209.

27. Zamorski MA, Biggs WS. Management of suspected fetal macrosomia. Am Fam Physician. 2001;63(2):302-6.

28. Agbozo F, Abubakari A, Der J, Jahn A. Prevalence of low birth weight, macrosomia and stillbirth and their relationship to associated maternal risk factors in Hohoe municipality, Ghana. Midwifery. 2016;40:200-6.

29. Pei L, Kang Y, Zhao Y, Cheng Y, Yan H. Changes in socioeconomic inequality of low birth weight and Macrosomia in Shaanxi Province of Northwest China, 2010-2013: a cross-sectional study. Medicine (Baltimore). 2016:95(5):e2471.

30. Mohammadbeigi A, Farhadifar F, Soufi Zadeh N, Mohammadsalehi N, Rezaiee M, Aghaei M. Fetal macrosomia: risk factors, maternal, and perinatal outcome. Ann Med Health Sci Res. 2013;3(4):546-50.

31. Usta A, Usta CS, Yildiz A, Ozcaglayan R, Dalkiran ES, Savkli A, et al. Frequency of fetal macrosomia and the associated risk factors in pregnancies without gestational diabetes mellitus. Pan Afr Med J. 2017;26:62.

\section{Publisher's Note}

Springer Nature remains neutral with regard to jurisdictional claims in published maps and institutional affiliations.

Ready to submit your research? Choose BMC and benefit from:

- fast, convenient online submission

- thorough peer review by experienced researchers in your field

- rapid publication on acceptance

- support for research data, including large and complex data types

- gold Open Access which fosters wider collaboration and increased citations

- maximum visibility for your research: over $100 \mathrm{M}$ website views per year

At $\mathrm{BMC}$, research is always in progress.

Learn more biomedcentral.com/submissions 